\title{
The Efficacy of Licensed-Indication Use of Donepezil and Memantine Monotherapies for Treating Behavioural and Psychological Symptoms of Dementia in Patients with Alzheimer's Disease: Systematic Review and Meta-Analysis
}

\author{
I.A. Lockhart ${ }^{\mathrm{a}}$ M.E. Orme ${ }^{\mathrm{b}}$ S.A. Mitchell ${ }^{\mathrm{c}}$ \\ a Pfizer Ltd., Tadworth, ${ }^{\mathrm{b}}$ ICERA Consulting Ltd., Swindon, and ' Abacus International, Bicester, UK
}

\section{Key Words}

Alzheimer disease - Behavioural/psychiatric symptoms of dementia - Behavioural medicine Community Mental Health Services $\cdot$ Geriatric psychiatry $\cdot$ Home nursing $\cdot$ Meta-analysis • Preventive psychiatry $\cdot$ Systematic reviews

\begin{abstract}
Background/Aims: Behavioural and psychological symptoms of dementia (BPSD) in Alzheimer's disease (AD) greatly increase caregiver burden. The abilities of donepezil and memantine to manage BPSD within their licensed indications in AD were compared. Methods: A systematic review, random effects meta-analysis and Bucher indirect comparison were conducted. Results: Six randomised controlled studies (4 donepezil and 2 memantine) reported use within the licensed indication and had Neuropsychiatric Inventory (NPI) data suitable for meta-analysis. BPSD showed significant improvement with donepezil compared with placebo [weighted mean difference (WMD) in NPI $-3.51,95 \%$ confidence interval $(\mathrm{Cl})-5.75,-1.27]$, whereas this was not the case for memantine (WMD $-1.65,95 \% \mathrm{Cl}-4.78,1.49$ ). WMD in NPI for donepezil versus memantine favoured donepezil but was not statistically significant $(-1.86,95 \% \mathrm{Cl}-5.71,1.99$; $p=0.34)$. Conclusion: Within its licensed indication, donepezil is efficacious for the management of BPSD in AD compared with placebo.

Copyright $\odot 2011$ S. Karger AG, Basel
\end{abstract}




\section{Introduction}

Alzheimer's disease (AD) is an incurable, neurodegenerative disease and is the most common cause of dementia. The non-cognitive, heterogeneous group of symptoms and behaviours occurring in people with dementia are termed behavioural and psychological symptoms of dementia (BPSD). These include severe mood changes, apathy, agitation, aggression, anxiety, depression and delusions [1]. AD is one of the most economically costly diseases to society, and a large proportion of this cost is the long-term care provided by health professionals and institutionalisation of patients in the severe disease stages [2].

Although BPSD are not included as core features in the definition of the dementia syndrome, about $66 \%$ of people with dementia will experience some BPSD at any one time point, and for 33\% of community-dwelling people with dementia the level of BPSD will be in the clinically significant range $[1,3,4]$. For people with dementia who are in institutional care, the figure for clinically significant BPSD rises to almost 80\% [5].

As home care is usually preferred by patients and families, the range of behavioural disturbances is an important risk factor for increasing caregiver burden and psychological distress $[6,7]$. BPSD are also a strong predictor for institutionalisation of patients with dementia $[8-10]$.

The traditional pharmacological management of BPSD (typical and atypical antipsychotics) has significant morbidity, including extrapyramidal signs and symptoms, gait abnormalities, sedation, an increased risk of falls and fractures, increased incidence of delirium, cerebrovascular adverse events and death $[11,12]$.

A treatment specifically for AD that is able to manage BPSD with an acceptable side effect profile is therefore highly desirable. Currently, cholinesterase inhibitors (ChEIs) are the standard of care for the treatment of cognitive deficits in patients with AD [13] and have fewer serious side effects than antipsychotics [12].

There is meta-analysis evidence that ChEIs as a class have a statistically significant benefit compared with placebo in treating symptoms of BPSD in patients with AD [14]. In particular, donepezil (licensed for the symptomatic treatment of mild to moderately severe AD), which contributed the majority of studies to this analysis (6 of 10 studies), was found to have a statistically significant benefit compared with placebo when analysed separately [14].

Memantine is a moderate-affinity, uncompetitive antagonist of $\mathrm{N}$-methyl-D-aspartate receptors, which is approved for the treatment of moderate to severe $\mathrm{AD}$. There are data to suggest that, in addition to its benefits on cognition, function and global status, memantine may also help alleviate behavioural symptoms [15]. A meta-analysis and 2 pooled analyses indicate that memantine confers benefit in the treatment of agitation and aggression over 3-6 months in patients with AD $[12,16,17]$.

However, to date no comparison has been made between donepezil and memantine to assess the relative efficacy of these two treatments, within their AD-licensed indications, for managing BPSD.

The current systematic review and meta-analysis of double-blind, placebo-controlled, randomised controlled trials (RCTs) were conducted to elucidate the efficacy of donepezil and memantine in managing BPSD in AD within their respective licensed indications and to compare their relative efficacy via an indirect comparison. 


\section{Methods}

Systematic Literature Search

Reports of double-blind, placebo-controlled RCTs of donepezil and/or memantine versus placebo were identified by searches of the following electronic databases (conducted on February 19, 2010):

- The Cochrane Library, incorporating

- the Central Register of Controlled Trials,

- the Cochrane Database of Systematic Reviews,

- the Database of Abstracts of Reviews of Effects and

- the Health Technology Assessment Database;

- OVID MEDLINE in process;

- OVID MEDLINE, 1950 to present day, and

- OVID EMBASE, 1980 to present day.

There was no restriction on language of publication. The search strategy included both free text and $\mathrm{MeSH}$ terms for $\mathrm{AD}$ and the interventions of interest. In addition to electronic databases, the following conference proceedings were searched for the period 2005-2010:

- International Conference on Alzheimer's Disease;

- European Federation of Neurological Societies Congress, and

- European College of Neuropsychopharmacology Congress.

Hand-searching was also performed by review of the bibliographies of included RCTs.

The full list of criteria for eligible studies is reported in table 1 . The inclusion and exclusion criteria were examined initially against the title and abstract of articles identified by the literature search. The full text of potentially eligible articles was then checked to confirm eligibility. This stage of the review was conducted in duplicate, with any discrepancies resolved through consensus.

The methodological quality of RCTs was assessed according to methods recommended in section six of the Cochrane Reviewer's handbook (version 5.0.2) [18] independently by two reviewers. The likelihood of bias according to three components was assessed: adequacy of randomisation and allocation concealment procedures, adequacy of blinding procedures and completeness of follow-up.

Data were extracted from eligible publications by a reviewer into an Excel ${ }^{\circledR}$ spreadsheet. A second reviewer checked the resulting extraction and any discrepancies were resolved through discussion.

Data of interest to be extracted from the studies meeting the review inclusion criteria included the stage of AD as measured by the Mini Mental State Examination (MMSE) score, setting (community, out-patient, assisted living and/or nursing home), total Neuropsychiatric Inventory (NPI) and MMSE scores at baseline, sample size in each treatment group, treatment and dose/schedule, concomitant medications and duration of study.

\section{Meta-Analysis Methodology}

In the meta-analysis, the outcome measure used was absolute change in NPI score compared with baseline NPI score based on a last-observation-carried-forward (LOCF) analysis since this was reported consistently across all included studies. Outcome measures at the 24week time point were used in the analysis where available. The inclusion criteria allowed for the inclusion of outcomes measured between 3 months and 1 year from baseline (as per the meta-analysis by Campbell et al. [14] in 2008).

The meta-analysis evaluated a pooled estimate of the weighted mean difference (WMD) in the change in NPI score between treatment arms. A random-effect meta-analysis was used to allow the true treatment effect to vary between studies due to heterogeneity. 
Table 1. Inclusion and exclusion criteria

\begin{tabular}{|c|c|c|}
\hline Criteria & Included & Excluded \\
\hline Population & $\begin{array}{l}\text { Age: } \geq 18 \text { years } \\
\text { Race: any } \\
\text { Qualifying disease: AD (diagnosed with established } \\
\text { criteria, e.g. DSM-IV and NINCDS-ADRDA) } \\
\text { Any severity of disease at baseline } \\
\text { Community-/nursing home-dwelling resident }\end{array}$ & Age: $\leq 18$ years \\
\hline $\begin{array}{l}\text { Perspective } \\
\text { of the study }\end{array}$ & $\begin{array}{l}\text { Prospective (concurrent) } \\
\text { Comparative }\end{array}$ & $\begin{array}{l}\text { Retrospective } \\
\text { (non-concurrent, historical) }\end{array}$ \\
\hline Type of the study & $\begin{array}{l}\text { RCT (open label or blinded) } \\
\text { Cross-over trials with a wash-out period between } \\
\text { treatments }\end{array}$ & $\begin{array}{l}\text { Non-randomised CCT: } \\
\text { Cohort } \\
\text { Observational } \\
\text { Case control } \\
\text { Cross sectional } \\
\text { Non-comparative study }\end{array}$ \\
\hline Language & All & None \\
\hline Study duration & Any & None \\
\hline Sample size & Any & None \\
\hline $\begin{array}{l}\text { Interventions/ } \\
\text { treatments }\end{array}$ & $\begin{array}{l}\text { Any dose of: } \\
\left.\text { - Donepezil (Aricept }{ }^{\circledR}\right) \\
\text { - Memantine }\left(\text { Ebixa }^{\circledR} \text { ) }\right.\end{array}$ & \\
\hline $\begin{array}{l}\text { Control } \\
\text { intervention/ } \\
\text { treatments }\end{array}$ & $\begin{array}{l}\text { Placebo/usual care } \\
\text { Any of the above interventions }\end{array}$ & \\
\hline $\begin{array}{l}\text { Included study } \\
\text { outcomes }\end{array}$ & $\begin{array}{l}\text { Global or individual BPSD using a validated } \\
\text { assessment instrument, i.e. } \\
\text { - NPI } \\
\text { - NPI-NH } \\
\text { - CMAI } \\
\text { - Apathy Scale } \\
\text { - BEHAVE-AD } \\
\text { - CERAD Behavioural Scale } \\
\text { - CSDD }\end{array}$ & $\begin{array}{l}\text { Efficacy only } \\
\text { Safety/tolerability }\end{array}$ \\
\hline
\end{tabular}

DSM-IV = Diagnostic and Statistical Manual of Mental Disorders; NINCDS-ADRDA = National Institute of Neurological and Communicative Disorders and Stroke and the Alzheimer Disease and Related Disorders Association; CCT = controlled clinical trial; NPI-NH = NPI-Nursing Home Version; CMAI = Cohen-Mansfield Agitation Inventory; BEHAVE-AD = Behavioural Pathologic Rating Scale for Alzheimer's Disease; CERAD = Consortium to Establish a Registry in AD; CSDD = Cornell Scale for Depression in Dementia.

The meta-analysis was conducted in Stata IC (version 10.1) using the metan package SJ9_2: sbe24_3 [19,20].

Adjusted indirect comparisons between donepezil and memantine (via the common comparator of placebo) were made using the method of Bucher et al. [21] to compare the WMD in NPI pooled across donepezil trials and the WMD in NPI pooled across memantine 


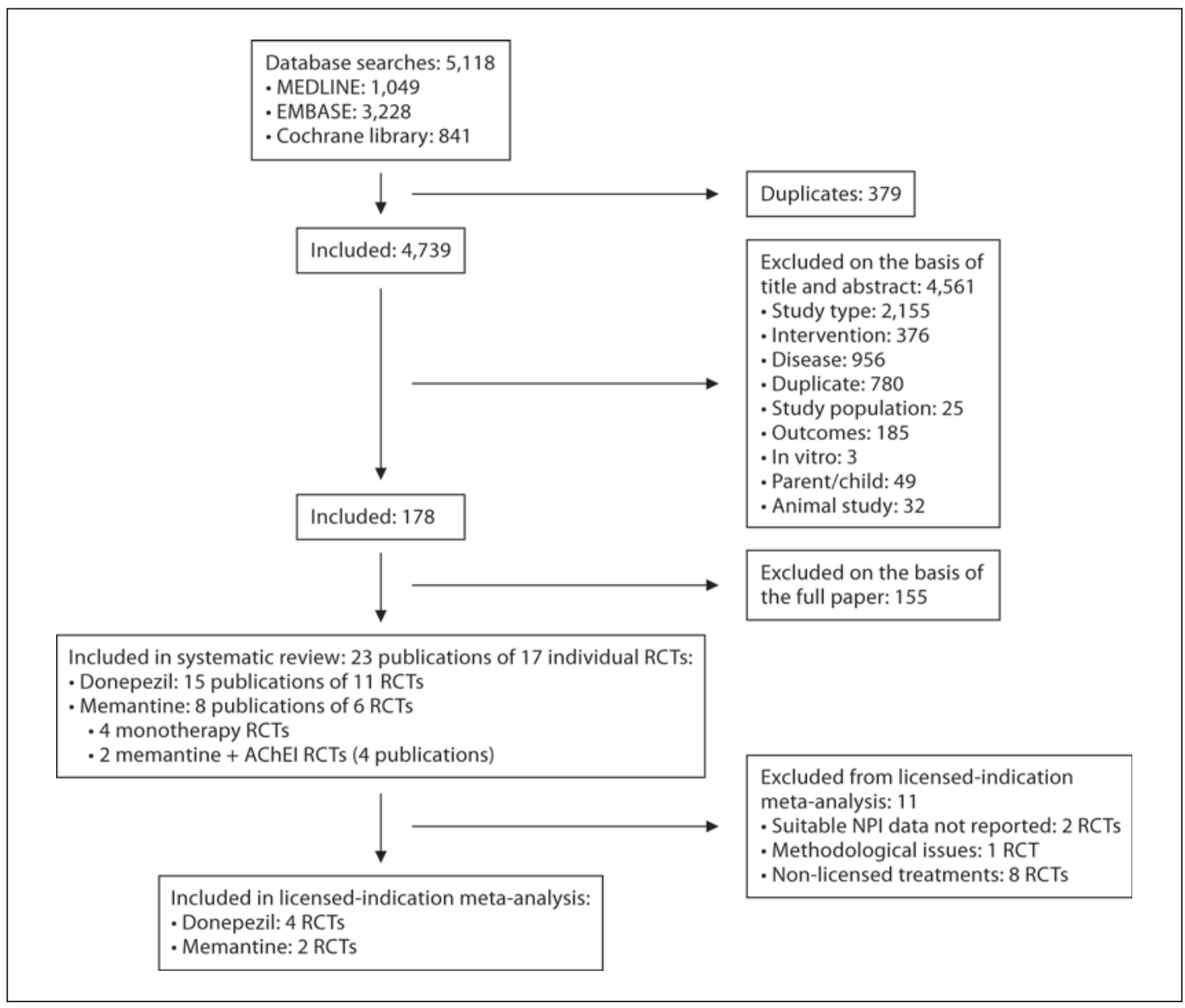

Fig. 1. Flow chart of inclusions/exclusions.

trials. This is, effectively, a meta-analysis stratified by drug intervention, and the method is advantageous because it maintains the randomisation as originally allocated.

\section{Assessment of Bias}

As per good meta-analysis practice, a formal assessment of publication bias was conducted by plotting a funnel plot with the Egger linear regression test of asymmetry [22, 23].

\section{Results}

\section{Systematic Literature Search Results}

Following removal of obvious duplicates, a total of 4,739 potentially relevant publications were identified for inclusion in the clinical systematic review, of which 4,561 were excluded on the basis of title and abstract (fig. 1). On re-application of the review inclusion criteria to the 178 full-text papers, a further 155 were excluded. Therefore, 23 publications detailing 17 RCTs met the inclusion criteria and were included in the systematic review [2446] (donepezil: 15 publications of 11 placebo-controlled RCTs, and memantine: 8 publications of 6 placebo-controlled RCTs). This included 4 memantine monotherapy RCTs [38-40, 
44] and 2 RCTs where patients stabilised on concomitant ChEIs were administered memantine or placebo as add-on therapy $[27,36]$.

Following data extraction, 2 RCTs were excluded on the basis of non-availability of NPI outcome data suitable for meta-analysis [24, 35]. One study [34] was excluded because of methodological quality concerns: this donepezil-versus-placebo study in 566 communitybased subjects, with baseline MMSE 19, was excluded because less than one fifth of the planned subjects $(n=3,000)$ were in fact randomised $(n<600)$ and attrition in the 1st year was $40 \%$. These and further methodological concerns have been documented previously [47].

Therefore, 14 trials were considered for inclusion in the meta-analysis. However, only 6 trials $(2$ memantine $[40,44]$ and 4 donepezil $[29,37,42,45])$ were monotherapy trials with medication used within their licensed indication and were included in the licensed-indication meta-analysis. The study by Gauthier et al. [29] (2002) was a substudy of that by Feldman et al. [32] (2001). The original publication [32] reported results from 290 subjects in a community-based or assisted-living setting and included patients with moderate to severe AD (MMSE 5-17). Donepezil is only licensed for use in patients with mild to moderately severe AD (MMSE 10-26) and not in patients with severe AD (MMSE <10). The study by Gauthier et al. [29] reported exclusively on the patients with moderate AD within the trial, and results from this subgroup were included in the licensed indication meta-analysis.

\section{Description of RCTs Included in the Meta-Analysis}

The baseline study characteristics of the 17 RCTs included in the systematic review are reported in tables 2-4. The 4 RCTs reporting results for donepezil used within its licensed indication in mild to moderately severe $\mathrm{AD}$ are described below:

Gauthier et al. [29]: 207 participants recruited from 32 sites from Canada, Australia and France, assessed at 24 weeks, in the community or assisted-living setting, mean age 74 years, mean baseline behavioural disturbance NPI 18 points and MMSE $\sim 14$, concomitant medication (psychotropics) permitted.

Holmes et al. [45]: 96 participants recruited from 16 sites in the UK, assessed at 24 weeks, presumed to be in the community although this was not stated specifically, mean age 79 years, mean baseline NPI 14-15 points, MMSE 21, concomitant psychotropics permitted (39\% donepezil group and $47 \%$ placebo group). The primary outcome was the change in NPI between week 12 (when randomisation occurred) and week 24 .

Johannsen et al. [42]: 202 participants recruited from 57 sites in Belgium, Denmark, Germany, Greece, Hungary, Iceland, The Netherlands, Poland and the USA, in the community or assisted-home-care setting, mean age 74 (donepezil group) and 71 years (comparator group), mean baseline NPI not given, MMSE $\sim 19$, concomitant psychotropics permitted (35\% donepezil group and 39\% comparator group).

Winblad et al. [37]: 286 participants recruited from 28 sites in Denmark, Finland, Norway, Sweden and The Netherlands, assessed (primary) at 52 weeks, out-patients, mean age 70 (donepezil group) and 60 years (placebo group), mean baseline NPI 12-13 points, MMSE $\sim 19$, concomitant psychotropics permitted (32\% donepezil group and $28 \%$ placebo group).

Baseline characteristics for the 2 memantine monotherapy RCTs used within its licensed indication in moderate to severe $\mathrm{AD}$ are described below:

Reisberg et al. [40]: 252 participants recruited from 32 centres in the USA, in the community, mean age 76 years, mean baseline NPI 20-21 points, MMSE $\sim 8$, certain concomitant medications were excluded, including anticonvulsants, antiparkinsonian agents, hypnotic agents, anxiolytic agents and neuroleptic agents. 
Dementia

and Geriatric
Dement Geriatr Cogn Disord Extra 2011;1:212-227

\begin{tabular}{|l|l|}
\hline DOI: 10.1159/000330032 & 2011 S. Karger AG, Basel \\
\hline
\end{tabular}

Published online: July 20, 2011

www.karger.com/dee

218

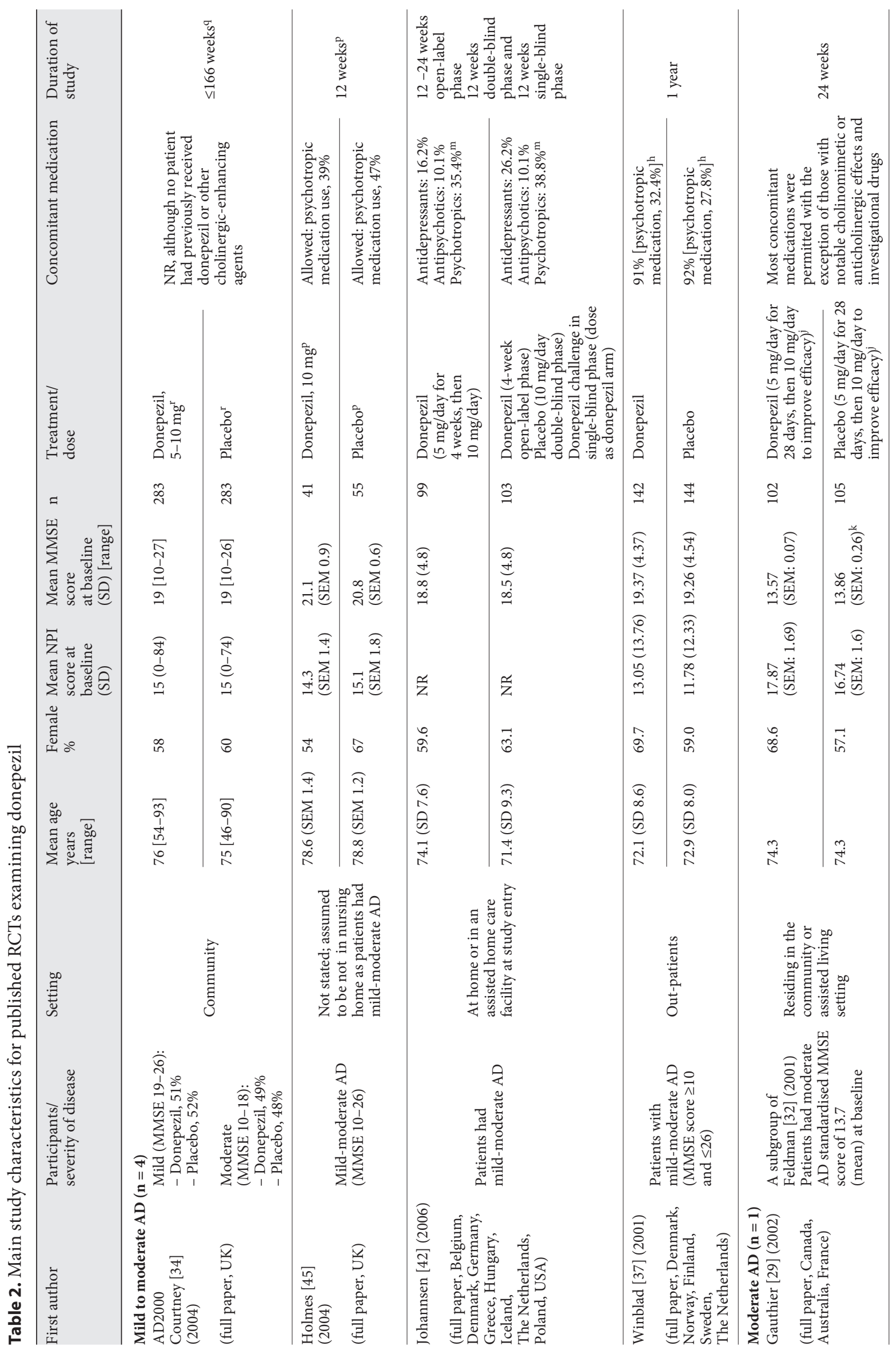


and Geriatric
Dementia

Dement Geriatr Cogn Disord Extra 2011;1:212-227

\begin{tabular}{|l|l|}
\hline DOI: 10.1159/000330032 & 2011 S. Karger AG, Basel
\end{tabular}

Published online: July 20, 2011

www.karger.com/dee

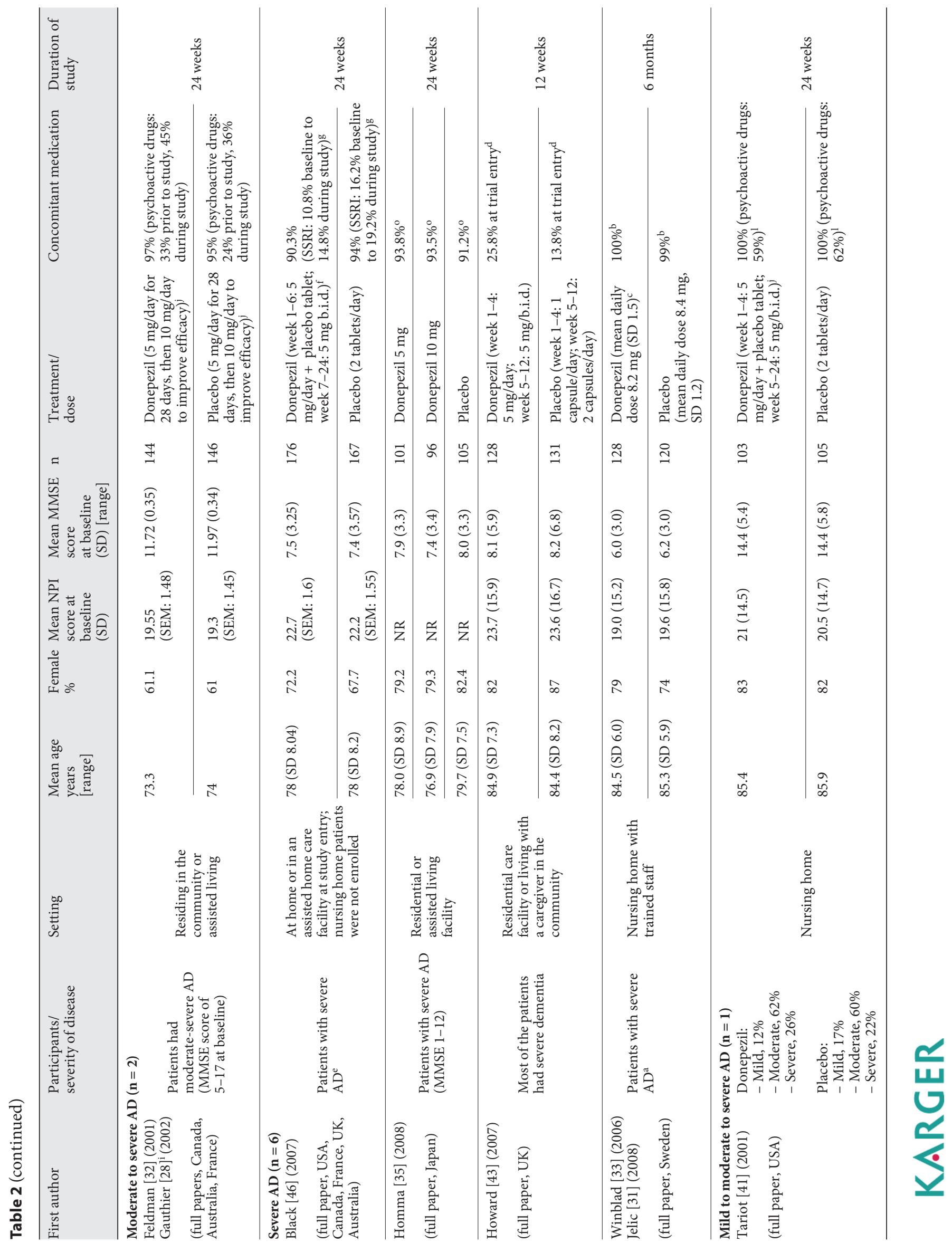


van Dyck et al. [44]: 350 participants recruited from 35 sites in the USA, in own or relative's home, mean age 78 years, mean baseline NPI 20 (memantine group) and 18 points (placebo group), MMSE 10, stable doses of antidepressants and antipsychotics permitted.

\section{Assessment of Bias}

Figure 2 illustrates the funnel plot used to detect publication bias. In the absence of bias, the funnel plot will be symmetrical and data points should fall within the $95 \%$ confidence interval (CI) limits. The regression line in figure 2 is fitted using the Egger linear regression test of asymmetry [23]. If there is asymmetry, with smaller studies showing effects that differ systematically from larger studies, the regression line will not pass through the origin. The regression line intercept is a measure of the asymmetry whereby the larger the deviation from zero the greater the asymmetry.

Although there is some asymmetry in the funnel plot indicating some potential for bias, funnel-plot asymmetry may also reflect other types of bias such as selection bias.

Table 2. Footnotes

$\mathrm{NR}=$ Not reported; SSRI = selective serotonin reuptake inhibitors

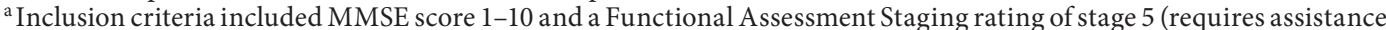
in choosing proper clothing) to 7c (non-ambulatory/unable to walk without assistance).

${ }^{b}$ Most commonly used classes of drugs were analgesics, laxatives, hypnotics, sedatives and anxiolytics, diuretics, drugs used to treat anaemia, antidepressants, drugs to treat rheumatic diseases and gout, antibacterial agents, and antipsychotic drugs. More than $80 \%$ of patients were taking psychoactive medications [breakdown by class as follows: hypnotics, sedatives, and anxiolytics, $61 \%$ (donepezil, $n=78$ ) vs. $58 \%$ (placebo, $n=70)$; antidepressants, $52 \%(n=67)$ vs. $51 \%(n=61)$; antipsychotics, $38 \%(\mathrm{n}=48)$ vs. $42 \%(\mathrm{n}=50)$, respectively].

c $5 \mathrm{mg}$ for the first 30 days followed by $10 \mathrm{mg}$ thereafter (or $5 \mathrm{mg}$ if not well tolerated).

$\mathrm{d} p=0.02$ between groups.

e The majority of patients had an MMSE score of 6-12 (68.8\% in the donepezil group and $68.3 \%$ in the placebo group).

${ }^{\mathrm{f}}$ Clinician was permitted to reduce the study medication to 1 blinded tablet per day if necessary after week 6 . The maximum dose of $10 \mathrm{mg} / \mathrm{day}$ was maintained by $85 \%$ of patients in the donepezil group at study endpoint.

g More than $20 \%$ of patients in either group were taking antiplatelet agents. The most common concomitant medications taken during the study (10\% in either group) included acetylsalicylic acid, multivitamins, tocopherol, risperidone, paracetamol, furosemide, levothyroxine sodium and ascorbic acid.

${ }^{\mathrm{h}}$ Percentage taking at least one concomitant medication over the course of the study. Antihypertensive drugs were used more frequently in the placebo (24/144) than in the donepezil (14/142) group.

${ }^{\mathrm{i}}$ Gauthier et al. [28] reported more elaborate results of NPI efficacy outcomes of the same patient population studied by Feldman et al. [32].

${ }^{\mathrm{j}} 10 \mathrm{mg} / \mathrm{day}$ the intended dose: study medication could be reduced to $5 \mathrm{mg} /$ day or placebo equivalent at any time during the study to improve tolerability.

${ }^{\mathrm{k}}$ One patient with a baseline standardised MMSE score of 18 was randomised into the trial.

${ }^{1}$ Patients receiving psychotropic medications were generally required to have been on stable doses for at least 1 month before screening. Adjustments in psychotropic medication use were discouraged, but were permitted if clinically necessary. Most concomitant medications were allowed, except those with significant cholinomimetic or anticholinergic effects and investigational drugs; patients treated with tacrine must have discontinued use of the agent at least 30 days before the screening visit.

m Stable doses of antidepressants (SSRIs) and low stable doses of atypical antipsychotics that were prescribed before study entry were allowed to be continued during the study.

${ }^{n}$ MMSE 21-26 at baseline.

${ }^{o}$ Placebo vs. donepezil 5 mg vs. donepezil $10 \mathrm{mg}$ : psychotropics, 29.4 vs. 27.1 vs. 23.9\%; cerebral circulation/metabolism enhancers, 9.8 vs. 9.4 vs. $9.8 \%$; hypnotics, 20.6 vs. 11.5 vs. $18.5 \%$; other, 37.3 vs. 32.3 vs. $41.3 \%$.

p Open-label phase: $5 \mathrm{mg} /$ day donepezil for 6 weeks followed by $10 \mathrm{mg} /$ day for further 6 weeks. Patients were then randomised to $10 \mathrm{mg} /$ day donepezil for further 6 weeks after a 12 -week open-label phase. If there was no marked cognitive decline (loss of $>2$ points on the MMSE compared with baseline) then randomised treatment continued for further 6 weeks.

q Treatment originally scheduled for 60 weeks (12-week run-in +48 -week maintenance treatment). However, following a protocol modification, there was an option to extend treatment indefinitely. [After a 6-week no-treatment washout, patients could continue with the same double-blind treatment that they had been receiving for 60 weeks for a further 48 weeks if they, their doctor and their carer judged that this course was appropriate. At the end of every 48 -week treatment period, a further 4-week treatment-free washout took place, whereupon patients could once again continue with another 48-week phase of double-blind treatment.]

${ }^{\mathrm{r}}$ Run-in treatment period of 12 weeks, in which patients were randomly allocated either to donepezil (5 mg/day) or placebo followed by a second randomisation to long-term donepezil (5 or $10 \mathrm{mg} /$ day) or placebo. 
Lockhart et al.: BPSD Outcomes for Donepezil versus Memantine

Table 3. Main study characteristics for published RCTs examining memantine monotherapy

\begin{tabular}{|c|c|c|c|c|c|c|c|c|c|c|}
\hline $\begin{array}{l}\text { First } \\
\text { author }\end{array}$ & $\begin{array}{l}\text { MMSE } \\
\text { score }\end{array}$ & Setting & $\begin{array}{l}\text { Mean } \\
\text { age } \\
\text { years } \\
(\mathrm{SD})\end{array}$ & $\begin{array}{l}\mathrm{Fe}- \\
\text { male } \\
\%\end{array}$ & $\begin{array}{l}\text { Mean } \\
\text { NPI } \\
\text { score at } \\
\text { baseline } \\
\text { (SD) }\end{array}$ & $\begin{array}{l}\text { Mean } \\
\text { MMSE } \\
\text { score at } \\
\text { baseline } \\
\text { (SD) }\end{array}$ & $\mathrm{n}$ & $\begin{array}{l}\text { Treatment/ } \\
\text { dose }\end{array}$ & $\begin{array}{l}\text { Con- } \\
\text { comitant } \\
\text { medication }\end{array}$ & $\begin{array}{l}\text { Study } \\
\text { duration } \\
\text { weeks }\end{array}$ \\
\hline \multicolumn{11}{|c|}{ Mild to moderate $\mathrm{AD}(\mathrm{n}=2)$} \\
\hline $\begin{array}{l}\text { Bakchine [38] } \\
\text { (2008) }\end{array}$ & \multirow{2}{*}{$\begin{array}{l}11-23 \\
\text { at baseline }\end{array}$} & \multirow{2}{*}{$\begin{array}{l}\text { Out- } \\
\text { patient }\end{array}$} & $74.0(7.4)$ & 65 & NA & $18.6(3.3)$ & $318^{\mathrm{i}}$ & $\begin{array}{l}\text { Memantine } \\
\text { (initial dose: } 5 \mathrm{mg} / \text { day } \\
\text { then: } 4 \times 5 \mathrm{mg} / \text { day) }\end{array}$ & \multirow{2}{*}{ Allowed ${ }^{c}$} & \multirow{2}{*}{24} \\
\hline $\begin{array}{l}\text { (full paper, } \\
\text { 12 European } \\
\text { countries) }\end{array}$ & & & $73.3(6.9)$ & 60 & NA & $18.9(3.2)$ & $152^{\mathrm{i}}$ & $\begin{array}{l}\text { Placebo } \\
\text { (initial dose: } 5 \mathrm{mg} / \text { day } \\
\text { then: } 4 \times 5 \mathrm{mg} / \text { day) })^{\mathrm{h}}\end{array}$ & & \\
\hline \multirow{3}{*}{$\begin{array}{l}\text { Peskind [39] } \\
\text { (2006) } \\
\text { (full paper, USA) }\end{array}$} & \multirow{3}{*}{$\begin{array}{l}10-22 \\
\text { at screening/ } \\
\text { baseline }\end{array}$} & \multirow{3}{*}{$\begin{array}{l}\text { Out- } \\
\text { patient }\end{array}$} & $78.0(7.3)$ & 60 & $11.5(13.2)$ & $17.4(3.7)$ & 201 & $\begin{array}{l}\text { Memantine } \\
\text { (initial dose: } 5 \mathrm{mg} / \text { day }\end{array}$ & NR & \multirow{3}{*}{$-24^{g}$} \\
\hline & & & & & & & & then: $4 \times 5 \mathrm{mg} /$ day $)^{\mathrm{h}}$ & & \\
\hline & & & $77.0(8.2)$ & 57 & $12.2(13)$ & $17.2(3.4)$ & 202 & $\begin{array}{l}\text { Placebo } \\
\text { (initial dose: } 5 \mathrm{mg} / \text { day } \\
\text { then: } 4 \times 5 \mathrm{mg} / \text { day })^{\mathrm{h}}\end{array}$ & NR & \\
\hline \multirow{3}{*}{$\begin{array}{l}\text { Moderate to severe } \\
\text { Reisberg [40] } \\
\text { (2003) } \\
\text { (full paper, USA) }\end{array}$} & \multirow{3}{*}{$\begin{array}{l}\text { e AD }(\mathbf{n} \\
3-14^{\mathrm{d}}\end{array}$} & \multirow{3}{*}{$\begin{array}{l}\text { Resident } \\
\text { in the } \\
\text { community }\end{array}$} & & & & & & & \multirow{3}{*}{$\begin{array}{l}\text { Exclusions } \\
\text { listed }^{\mathrm{b}}\end{array}$} & \multirow{3}{*}{$\begin{array}{l}28 \text { mean } \\
\text { for both } \\
\text { groups } 24 \\
(\mathrm{SD} \pm 8)\end{array}$} \\
\hline & & & $75.5(8.16)$ & 72.2 & 21.4 & $7.8(3.76)$ & $126^{\mathrm{e}}$ & Memantine (20 mg) & & \\
\hline & & & $75.8(7.28)$ & 65.5 & 19.5 & $8.1(3.60)$ & $126^{\mathrm{e}}$ & Placebo (20 mg) & & \\
\hline \multirow{3}{*}{$\begin{array}{l}\text { van Dyck [44] } \\
(2007) \\
\text { (full paper, USA) }\end{array}$} & \multirow{3}{*}{$\begin{array}{l}5-14 \\
\text { at screening/ } \\
\text { baseline }\end{array}$} & \multirow{3}{*}{$\begin{array}{l}\text { Own or } \\
\text { relative's } \\
\text { home }\end{array}$} & $78.1(8.2)$ & 72.5 & $20.3(15.7)$ & $10.0(2.8)$ & 178 & $\begin{array}{l}\text { Memantine } \\
\text { (initial dose: } 5 \mathrm{mg} / \text { day }\end{array}$ & $97.2 \%^{\mathrm{a}}$ & \multirow{3}{*}{$-24^{g}$} \\
\hline & & & & & & & & then: $4 \times 5 \mathrm{mg} /$ day $)^{\mathrm{f}}$ & & \\
\hline & & & $78.3(7.6)$ & 70.3 & $17.5(16.4)$ & $10.3(3.1)$ & 172 & $\begin{array}{l}\text { Placebo } \\
\text { (initial dose: } 5 \mathrm{mg} / \text { day } \\
\text { then: } 4 \times 5 \mathrm{mg} / \text { day) }{ }^{\mathrm{f}}\end{array}$ & $97.1 \%^{\mathrm{a}}$ & \\
\hline
\end{tabular}

\footnotetext{
a The most common concomitant medications included acetylsalicylic acid, tocopherol, multivitamins and acetaminophen.

${ }^{b}$ Patients receiving the following concomitant medications were excluded: anticonvulsant agents, antiparkinsonian agents, hypnotic agents, anxiolytic agents, neuroleptic agents, cholinomimetic agents or any other investigational compounds.

${ }^{c}$ Selective serotonin reuptake inhibitors, oestrogens, anti-inflammatory drugs, $\beta$-blockers, insulin and $\mathrm{H}_{2}$ blockers were allowed if dose and medication had been stable for at least 3 months and were kept stable during study; only non-opioid analgesics could be administered chronically; vitamin E, coenzyme Q and atypical antipsychotics were allowed if dose and medication had been stable for at least 30 days and kept stable during study; atypical antipsychotics were not to be taken 3 days before a visit.

d Stage 5 or 6 on the Global Deterioration Scale, and stage $\geq 6$ a on the Functional Assessment Staging instrument.

e Detailed patient information reported from only those completing the study: $n=97$.

${ }_{\mathrm{f}}^{\mathrm{f}}$ Dose adjustments were permitted between weeks 3 and 8 for participants experiencing adverse events; however, participants unable to tolerate $20 \mathrm{mg} /$ day by the end of week 8 were excluded from the study.

${ }^{g}$ A 1- to 2-week single-blind placebo run-in phase was completed before randomisation to assess compliance and to minimise treatment response at baseline.

${ }^{\mathrm{h}}$ Transient dose adjustments were permitted between weeks 3 and 8 for participants experiencing dose-limiting adverse events; however, all were required to receive the target dose of $20 \mathrm{mg} /$ day by the end of week 8 .

${ }^{i}$ The patients were randomised in a 2:1 ratio, to minimise patient exposure to placebo due to ethical considerations (availability of efficient symptomatic drugs for AD in the majority of countries).
}

\section{Meta-Analysis}

The analysis was subgrouped by disease severity (MMSE score at baseline) as per licensed indication (fig. 3).

For the licensed indication of donepezil (fig. 3, mild to moderate AD), a meta-analysis of 4 RCTs reported a statistically significant improvement in BPSD versus placebo as measured by NPI total score (WMD -3.51, 95\% CI -5.75, -1.27 ; $\mathrm{I}^{2}=44.8 \%$ ).

In contrast, a meta-analysis of the 2 memantine monotherapy licensed-indication RCTs (fig. 3, moderate to severe AD) found no significant difference compared with placebo on NPI total score (WMD $-1.65,95 \%$ CI $-4.78,1.49 ; \mathrm{I}^{2}=25.3 \%$ ). For both results, the level of 
Lockhart et al.: BPSD Outcomes for Donepezil versus Memantine

Table 4. Main study characteristics for published RCTs examining memantine as add-on therapy to stable donepezil/ChEI

\begin{tabular}{|c|c|c|c|c|c|c|c|c|c|c|}
\hline $\begin{array}{l}\text { First } \\
\text { author }\end{array}$ & $\begin{array}{l}\text { Participants/ } \\
\text { severity of } \\
\text { disease }\end{array}$ & Setting & $\begin{array}{l}\text { Age } \\
\text { years } \\
\text { (SD) }\end{array}$ & $\begin{array}{l}\mathrm{Fe}- \\
\text { male } \\
\%\end{array}$ & $\begin{array}{l}\text { NPI score } \\
\text { at baseline } \\
\text { (SD) }\end{array}$ & $\begin{array}{l}\text { MMSE } \\
\text { score at } \\
\text { baseline } \\
\text { (SD) }\end{array}$ & $\mathrm{n}$ & $\begin{array}{l}\text { Treatment/ } \\
\text { dose }\end{array}$ & Concomitant medication & $\begin{array}{l}\text { Study } \\
\text { duration } \\
\text { weeks }\end{array}$ \\
\hline \multicolumn{11}{|c|}{ Mild to moderate $\mathrm{AD}(\mathrm{n}=1)$} \\
\hline \multirow[t]{2}{*}{$\begin{array}{l}\text { Porsteinsson } \\
{[36](2008)}\end{array}$} & \multirow{2}{*}{$\begin{array}{l}\text { Patients } \\
\text { had mild- } \\
\text { moderate } \\
\mathrm{AD}^{\mathrm{i}}\end{array}$} & \multirow{2}{*}{$\begin{array}{l}\text { Resident } \\
\text { in the } \\
\text { community }\end{array}$} & $\begin{array}{l}74.9 \\
(7.64)\end{array}$ & 53.9 & $\begin{array}{l}11.8 \\
(13.11)\end{array}$ & $\begin{array}{l}16.7 \\
(3.67)\end{array}$ & 217 & $\begin{array}{l}\text { Memantine } \\
\text { (initial dose: } \\
5 \mathrm{mg} / \text { day; } \\
\text { then: } \\
4 \times 5 \mathrm{mg} / \text { day) }\end{array}$ & $\begin{array}{l}\text { Donepezil }(\mathrm{n}=154,71.0 \%) \\
9.5 \pm 1.5 \mathrm{mg} / \text { day } \\
\text { Rivastigmine }(\mathrm{n}=33,15.2 \%) \\
9.2 \pm 2.8 \mathrm{mg} / \text { day; } \\
\text { Galantamine }(\mathrm{n}=30,13.8 \%)\end{array}$ & \multirow[t]{2}{*}{24} \\
\hline & & & $\begin{array}{l}76 \\
(8.43)\end{array}$ & 50.5 & $\begin{array}{l}12.3 \\
(13.28)\end{array}$ & $\begin{array}{l}17.0 \\
(3.64)\end{array}$ & 216 & $\begin{array}{l}\text { Placebo } \\
\text { (initial dose: } \\
5 \mathrm{mg} / \text { day; } \\
\text { then: } \\
4 \times 5 \mathrm{mg} / \text { day) }{ }^{\mathrm{a}}\end{array}$ & $\begin{array}{l}\text { Donepezil }(\mathrm{n}=137,63.4 \%) \\
8.9 \pm 2.1 \mathrm{mg} / \text { day } \\
\text { Rivastigmine }(\mathrm{n}=44,20.4 \%) \\
10 \pm 2.6 \mathrm{mg} / \text { day } \\
\text { Galantamine }(\mathrm{n}=35,16.2 \%)\end{array}$ & \\
\hline \multirow{2}{*}{$\begin{array}{l}\text { Moderate to ser } \\
\text { Tariot [27] } \\
(2004) \\
\text { Cummings [26] } \\
(2006)^{\mathrm{d}} \\
\text { van Dyck [25] } \\
(2006)^{\mathrm{d}} \\
\text { (full paper, } \\
\text { USA) }\end{array}$} & \multirow{2}{*}{$\begin{array}{l}\text { Patients had } \\
\text { moderate- } \\
\text { severe } \mathrm{AD}^{\mathrm{a}}\end{array}$} & \multirow{2}{*}{$\begin{array}{l}\text { Resident } \\
\text { in the } \\
\text { community }\end{array}$} & $\begin{array}{l}75.5 \\
(8.45)\end{array}$ & 63 & $\begin{array}{l}13.4 \\
\text { (SEM: 1.07) }\end{array}$ & $\begin{array}{l}9.9 \\
(3.13)\end{array}$ & 203 & $\begin{array}{l}\text { Memantine } \\
(\text { week 1-4: } \\
5 \mathrm{mg} / \text { day; } \\
\text { week 5-24: } \\
4 \times 5 \mathrm{mg} / \text { day })^{\mathrm{b}}\end{array}$ & $97.5 \%^{\mathrm{c}}$ & \multirow{2}{*}{24} \\
\hline & & & $\begin{array}{l}75.5 \\
(8.73)\end{array}$ & 67 & $\begin{array}{l}13.4 \\
\text { (SEM: 1.08) }\end{array}$ & $\begin{array}{l}10.2 \\
(2.98)\end{array}$ & 201 & $\begin{array}{l}\text { Placebo } \\
\text { (week 1-4: } \\
5 \mathrm{mg} / \text { day; } \\
\text { week 5-24: } \\
4 \times 5 \mathrm{mg} / \text { day) }\end{array}$ & $98 \%^{\mathrm{c}}$ & \\
\hline
\end{tabular}

\footnotetext{
a Dose adjustments were permitted between weeks 3-8 for participants experiencing adverse effects.

${ }^{\mathrm{b}}$ All patients were to maintain stable donepezil therapy at entry dose as prescribed by the patient's physician for the duration of the study.

${ }^{\prime}$ The most frequent medication classes (>20\%) used during treatment with memantine were vitamins (77\%), analgesics (48\%), antidepressants (36\%), mineral supplements (27\%), lipid-reducing agents (25\%), anxiolytics/neuroleptics (22\%), and anti-inflammatory agents (24\%).

${ }^{d}$ Cummings et al. [26] reported more in-depth results of NPI efficacy outcomes of the same patient population studied by Tariot et al. [27].
}

variation in the treatment effects due to heterogeneity was considered acceptable, since $\mathrm{I}^{2}$ $\geq 50 \%$ is generally regarded to represent considerable or substantial heterogeneity requiring further exploration [18].

\section{Indirect Comparison}

Based on the WMD in NPI shown in figure 3, an adjusted indirect comparison found that the WMD in NPI between donepezil and memantine was not statistically significant $(-1.86 ; 95 \%$ CI $-5.71,1.99 ; \mathrm{p}=0.34)$.

\section{Discussion}

Results from the present meta-analysis indicate that BPSD as measured by total NPI showed statistically significant improvement with donepezil monotherapy within its licensed indication (mild to moderately severe AD) compared with placebo (WMD -3.51, 95\% CI $-5.75,-1.27)$. In contrast, there was no statistically significant difference between memantine monotherapy used per its license in moderate to severe AD and placebo (WMD -1.65 , $95 \% \mathrm{CI}-4.78,1.49$ ). An indirect comparison numerically favoured donepezil versus memantine, but the difference was not statistically significant $(\mathrm{p}=0.34)$. 
Fig. 2. Funnel plot of mean difference (MD) in NPI score (LOCF) plotted against standard error.

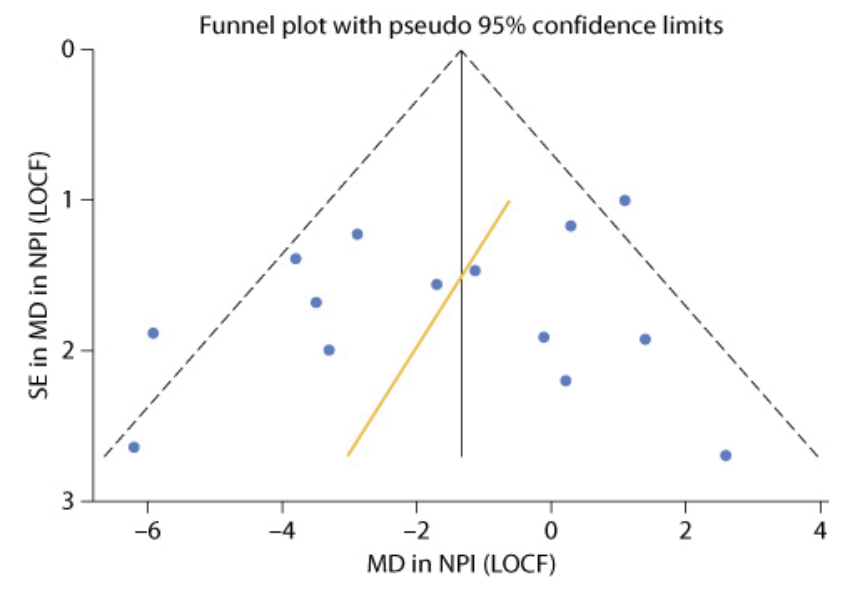

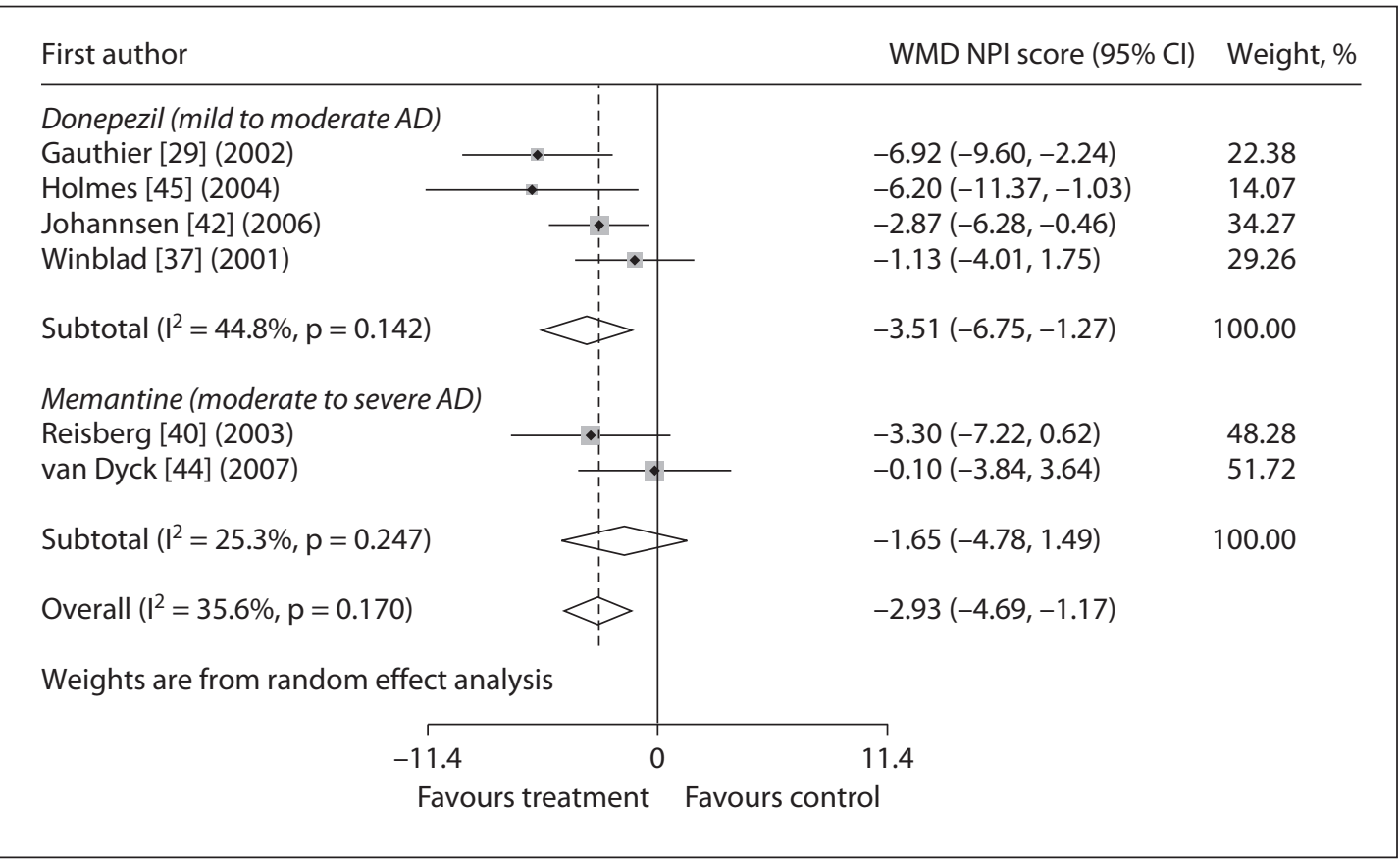

Fig. 3. Forest plot of random-effect meta-analysis for studies reporting use in licensed indication: donepezil, mild to moderately severe $\mathrm{AD}$ population, and memantine monotherapy, moderate to severe $\mathrm{AD}$ population. Note: ChEIs are also used in the placebo control arm; $\mathrm{I}^{2}=$ Variation in effect attributable to heterogeneity.

The clinical relevance of a statistically significant WMD in total NPI score of -3.51 for donepezil is broadly in line with a change in NPI of 4 points, which is likely to confer a modest clinical benefit [48]. However, there is still some debate as to what constitutes a clinically meaningful change in the NPI score, since a change measured by the scale is not always replicated by a comprehensive assessment conducted by experienced clinical staff [48]. This issue is exacerbated by the fact that BPSD is a complex cluster of signs and symptoms that 
fluctuates over time. Nevertheless, evidence from the present meta-analysis suggests that within its licensed indication, donepezil may offer modest alleviation from BPSD, and given that it is generally well tolerated in this population [47], it is an appropriate initial choice of pharmacotherapy for the management of these symptoms.

These data, focusing on licensed-indication use of donepezil and memantine, run contrary to the view that memantine may be effective for the management of BPSD [49]. The current review demonstrates that the evidence, within their respective licensed indications, is in fact stronger for donepezil. It is of interest to examine the licensed-indication results in the context of previous systematic reviews and meta-analyses. Of reviews supporting the use of memantine in BPSD, most relate to patients with moderate to severe $[15,16,50,51]$ or moderately severe to severe $\mathrm{AD}$ [17]. Within the licensed indication of memantine, meta-analyses have found a statistically significant difference in total NPI versus placebo $[16,50,51]$ or in the proportion of patients with improvement in neuropsychiatric cluster sub-items of the NPI (agitation/aggression, delusions or hallucinations) [17]. These meta-analyses of patients with moderate to severe $\mathrm{AD}(\mathrm{MMSE}<20)$ or moderately severe to severe $\mathrm{AD}$, respectively, have pooled trials where memantine was an add-on therapy (to a stable dose of donepezil or other ChEI) $[27,36]$, with memantine monotherapy trials. The only 2 monotherapy trials of memantine within its licensed indication that are used in these 5 reviews [40, 44], as reiterated recently [15], did not find a statistically significant difference in total NPI with memantine monotherapy versus placebo. Our results indicate that in spite of combining the data from these 2 trials, the effect of memantine on total NPI versus placebo remains statistically nonsignificant.

The Cochrane review of donepezil in dementia due to $\mathrm{AD}$ [47] reported that patients with mild-moderate $\mathrm{AD}$ benefited from donepezil treatment, including a reduction in behavioural disturbance. A later review [14] of all ChEIs (9 donepezil studies, 2 galantamine and 1 rivastigmine) reported a statistically significant effect on BPSD versus placebo in patients with mild to moderate AD but not among patients with moderate to severe AD. Our data lend further support to these reviews' conclusions, as related to donepezil in mild to moderate AD.

The structured literature search including conference abstracts and the methodological quality of the included articles being assessed by two individuals separately contribute to the strength of evidence provided by this systematic review. Further, with the exception of study duration, which varied from 12 weeks to 1 year for donepezil studies, the licensed-indication meta-analysis involved broadly comparable RCTs.

Regarding limitations, potential sources of residual reporting bias may stem from publication bias in that our search strategy reviewed only published data; unpublished data, grey literature (from the System for Information on Grey Literature in Europe) and ongoing studies were not sought. Some time lag bias may also have resulted from the search strategy including conference proceedings from a relatively narrow time window, 2005-2010, which may have yielded positive findings but not yet given enough time for negative findings to be published, the latter being typically published with some degree of time lag compared with positive findings.

Our review was also limited by the small number of licensed-indication trials, particularly for memantine monotherapy. The focus on total NPI was necessary as this was the most frequently reported outcome. Studies reporting BPSD outcomes as measured by other scales (e.g. the Behavioural Pathologic Rating Scale for Alzheimer's Disease or Apathy Scale) [24, 35], or by individual NPI items or item clusters without total NPI were, therefore, not included. Due to fundamental differences between the scales it was not possible to convert results to a comparable measure on the NPI scale. With regard to NPI subscales, data were not reported in a sufficient number of studies to make a meta-analysis feasible. 
In summary, the present review contributes to rational health care decisions by presenting the current relative strength of evidence for the licensed use of donepezil or memantine in the management of BPSD. Donepezil monotherapy within its licensed indication is significantly more efficacious than placebo for alleviating BPSD, whereas memantine monotherapy within its licensed indication has no statistically significant advantage over placebo in managing BPSD. An adjusted indirect comparison indicated a numerical but statistically non-significant trend favouring donepezil versus memantine in the management of BPSD. However, given that both treatments are licensed for different $\mathrm{AD}$ populations (donepezil for mild to moderately severe $\mathrm{AD}$ and memantine for moderate to severe $\mathrm{AD}$ ), application of an indirect comparison, which in this case is necessarily based on the respective performance of each drug relative to a different $\mathrm{AD}$ population, may have limited value.

\section{Disclosure Statement}

Development of this review and its manuscript was sponsored by Pfizer Ltd. (UK). M.E.O. and S.A.M. were paid consultants to Pfizer in connection with the development of the manuscript. I.A.L. is an employee of Pfizer.

\section{References}

1 McKeith I, Cummings J: Behavioural changes and psychological symptoms in dementia disorders. Lancet Neurol 2005;4:735-742.

2 Alzheimer's Disease International: World Alzheimer Report 2010: The global economic impact of dementia (http://www.alz.org/documents/national/World_Alzheimer_Report_2010.pdf).

-3 Lawlor B: Managing behavioural and psychological symptoms in dementia. Br J Psychiatry 2002;181: 463-465.

-4 Lyketsos CG, Steinberg M, Tschanz JT, Norton MC, Steffens DC, Breitner JC: Mental and behavioral disturbances in dementia: findings from the Cache County study on memory in aging. Am J Psychiatry 2000;157:708-714.

-5 Margallo-Lana M, Swann A, O’Brien J, Fairbairn A, Reichelt K, Potkins D, Mynt P, Ballard C: Prevalence and pharmacological management of behavioural and psychological symptoms amongst dementia sufferers living in care environments. Int J Geriatr Psychiatry 2001;16:39-44.

-6 Kinney JM, Stephens MA: Caregiving hassles scale: assessing the daily hassles of caring for a family member with dementia. Gerontologist 1989;29:328-332.

7 Hamel M, Gold DP, Andres D, Reis M, Dastoor D, Grauer H, Bergman H: Predictors and consequences of aggressive behavior by community-based dementia patients. Gerontologist 1990;30:206-211.

8 Colerick EJ, George LK: Predictors of institutionalization among caregivers of patients with Alzheimer's disease. J Am Geriatr Soc 1986;34:493-498.

-9 Steele C, Rovner B, Chase GA, Folstein M: Psychiatric symptoms and nursing home placement of patients with Alzheimer's disease. Am J Psychiatry 1990;147:1049-1051.

-10 O'Donnell BF, Drachman DA, Barnes HJ, Peterson KE, Swearer JM, Lew RA: Incontinence and troublesome behaviors predict institutionalization in dementia. J Geriatr Psychiatry Neurol 1992;5: $45-52$.

-11 Rochon PA, Normand SL, Gomes T, Gill SS, Anderson GM, Melo M, Sykora K, Lipscombe L, Bell CM, Gurwitz JH: Antipsychotic therapy and short-term serious events in older adults with dementia. Arch Intern Med 2008;168:1090-1096.

- 12 Ballard CG, Gauthier S, Cummings JL, Brodaty H, Grossberg GT, Robert P, Lyketsos CG: Management of agitation and aggression associated with Alzheimer disease. Nat Rev Neurol 2009;5:245-255.

-13 Doody RS, Dunn JK, Clark CM, Farlow M, Foster NL, Liao T, Gonzales N, Lai E, Massman P: Chronic donepezil treatment is associated with slowed cognitive decline in Alzheimer's disease. Dement Geriatr Cogn Disord 2001;12:295-300. 
-14 Campbell N, Ayub A, Boustani MA, Fox C, Farlow M, Maidment I, Howards R: Impact of cholinesterase inhibitors on behavioral and psychological symptoms of Alzheimer's disease: a meta-analysis. Clin Interv Aging 2008;3:719-728.

-15 Grossberg GT, Pejovic V, Miller ML, Graham SM: Memantine therapy of behavioral symptoms in community-dwelling patients with moderate to severe Alzheimer's disease. Dement Geriatr Cogn Disord 2009;27:164-172.

-16 Gauthier S, Loft H, Cummings J: Improvement in behavioural symptoms in patients with moderate to severe Alzheimer's disease by memantine: a pooled data analysis. Int J Geriatr Psychiatry 2008;23: 537-545.

-17 Wilcock GK, Ballard CG, Cooper JA, Loft H: Memantine for agitation/aggression and psychosis in moderately severe to severe Alzheimer's disease: a pooled analysis of 3 studies. J Clin Psychiatry 2008; 69:341-348

18 Higgins JPT, Green S: Cochrane Handbook for Systematic Reviews of Interventions (version 5.0.2, updated September 2009). Cochrane Collaboration, 2009 (www.cochrane-handbook.org).

-19 Harris R, Bradburn M, Deeks J, Harbord R, Altman D, Sterne J: Metan: fixed- and random-effects meta-analysis. Stata J 2008;8:3-28.

20 Software updates (metan). Stata J 2008;8:594

-21 Bucher HC, Guyatt GH, Griffith LE, Walter SD: The results of direct and indirect treatment comparisons in meta-analysis of randomized controlled trials. J Clin Epidemiol 1997;50:683-691.

-22 Sutton A, Duval S, Tweedie R, Abrams K, Jones D: Empirical assessment of effect of publication bias on meta-analyses. BMJ 2000;320:1574-1577.

-23 Egger M, Davey Smith G, Schneider M, Minder C: Bias in meta-analysis detected by a simple, graphical test. BMJ 1997;315:629-634.

-24 Seltzer B, Zolnouni P, Nunez M, Goldman R, Kumar D, Ieni J, Richardson S: Efficacy of donepezil in early-stage Alzheimer disease: a randomized placebo-controlled trial. Arch Neurol 2004;61:1852-1856.

25 van Dyck CH, Schmitt FA, Olin JT: A responder analysis of memantine treatment in patients with Alzheimer disease maintained on donepezil. Am J Geriatr Psychiatry 2006;14:428-437.

-26 Cummings JL, Schneider E, Tariot PN, Graham SM: Behavioral effects of memantine in Alzheimer disease patients receiving donepezil treatment. Neurology 2006;67:57-63.

-27 Tariot PN, Farlow MR, Grossberg GT, Graham SM, McDonald S, Gergel I: Memantine treatment in patients with moderate to severe Alzheimer disease already receiving donepezil: a randomized controlled trial. JAMA 2004;291:317-324.

-28 Gauthier S, Feldman H, Hecker J, Vellas B, Ames D, Subbiah P, Whalen E, Emir B: Efficacy of donepezil on behavioral symptoms in patients with moderate to severe Alzheimer's disease. Int Psychogeriatr 2002; 14:389-404.

-29 Gauthier S, Feldman H, Hecker J, Vellas B, Emir B, Subbiah P: Functional, cognitive and behavioral effects of donepezil in patients with moderate Alzheimer's disease. Curr Med Res Opin 2002;18: 347-354.

-30 Feldman H, Gauthier S, Hecker J, Vellas B, Xu Y, Ieni JR, Schwam EM: Efficacy and safety of donepezil in patients with more severe Alzheimer's disease: a subgroup analysis from a randomized, placebo-controlled trial. Int J Geriatr Psychiatry 2005;20:559-569.

-31 Jelic V, Haglund A, Kowalski J, Langworth S, Winblad B: Donepezil treatment of severe Alzheimer's disease in nursing home settings. A responder analysis. Dement Geriatr Cogn Disord 2008;26:458466.

- 32 Feldman H, Gauthier S, Hecker J, Vellas B, Subbiah P, Whalen E: A 24-week, randomized, doubleblind study of donepezil in moderate to severe Alzheimer's disease. Neurology 2001;57:613-620.

-33 Winblad B, Kilander L, Eriksson S, Minthon L, Batsman S, Wetterholm AL, Jansson-Blixt C, Haglund A: Donepezil in patients with severe Alzheimer's disease: double-blind, parallel-group, placebocontrolled study. Lancet 2006;367:1057-1065.

-34 Courtney C, Farrell D, Gray R, Hills R, Lynch L, Sellwood E, Edwards S, Hardyman W, Raftery J, Crome P, Lendon C, Shaw H, Bentham P: Long-term donepezil treatment in 565 patients with Alzheimer's disease (AD2000): randomised double-blind trial. Lancet 2004;363:2105-2115.

-35 Homma A, Imai Y, Tago H, Asada T, Shigeta M, Iwamoto T, Takita M, Arimoto I, Koma H, Ohbayashi T: Donepezil treatment of patients with severe Alzheimer's disease in a Japanese population: results from a 24-week, double-blind, placebo-controlled, randomized trial. Dement Geriatr Cogn Disord 2008;25:399-407. 
-36 Porsteinsson AP, Grossberg GT, Mintzer J, Olin JT: Memantine treatment in patients with mild to moderate Alzheimer's disease already receiving a cholinesterase inhibitor: a randomized, doubleblind, placebo-controlled trial. Curr Alzheimer Res 2008;5:83-89.

-37 Winblad B, Engedal K, Soininen H, Verhey F, Waldemar G, Wimo A, Wetterholm AL, Zhang R, Haglund A, Subbiah P: A 1-year, randomized, placebo-controlled study of donepezil in patients with mild to moderate AD. Neurology 2001;57:489-495.

-38 Bakchine S, Loft H: Memantine treatment in patients with mild to moderate Alzheimer's disease: results of a randomised, double-blind, placebo-controlled 6-month study. J Alzheimers Dis 2008;13: 97-107.

-39 Peskind ER, Potkin SG, Pomara N, Ott BR, Graham SM, Olin JT, McDonald S: Memantine treatment in mild to moderate Alzheimer disease: a 24-week randomized, controlled trial. Am J Geriatr Psychiatry 2006;14:704-715.

-40 Reisberg B, Doody R, Stoffler A, Schmitt F, Ferris S, Mobius HJ: Memantine in moderate-to-severe Alzheimer's disease. N Engl J Med 2003;348:1333-1341.

- 41 Tariot PN, Cummings JL, Katz IR, Mintzer J, Perdomo CA, Schwam EM, Whalen E: A randomized, double-blind, placebo-controlled study of the efficacy and safety of donepezil in patients with Alzheimer's disease in the nursing home setting. J Am Geriatr Soc 2001;49:1590-1599.

-42 Johannsen P, Salmon E, Hampel H, Xu Y, Richardson S, Qvitzau S, Schindler R: Assessing therapeutic efficacy in a progressive disease: a study of donepezil in Alzheimer's disease. CNS Drugs 2006;20: $311-325$.

-43 Howard RJ, Juszczak E, Ballard CG, Bentham P, Brown RG, Bullock R, Burns AS, Holmes C, Jacoby R, Johnson T, Knapp M, Lindesay J, O’Brien JT, Wilcock G, Katona C, Jones RW, DeCesare J, Rodger M: Donepezil for the treatment of agitation in Alzheimer's disease. N Engl J Med 2007;357:13821392.

-44 van Dyck CH, Tariot PN, Meyers B, Malca Resnick E: A 24-week randomized, controlled trial of memantine in patients with moderate-to-severe Alzheimer disease. Alzheimer Dis Assoc Disord 2007; 21:136-143.

-45 Holmes C, Wilkinson D, Dean C, Vethanayagam S, Olivieri S, Langley A, Pandita-Gunawardena ND, Hogg F, Clare C, Damms J: The efficacy of donepezil in the treatment of neuropsychiatric symptoms in Alzheimer disease. Neurology 2004;63:214-219.

-46 Black SE, Doody R, Li H, McRae T, Jambor KM, Xu Y, Sun Y, Perdomo CA, Richardson S: Donepezil preserves cognition and global function in patients with severe Alzheimer disease. Neurology 2007; 69:459-469.

47 Birks J, Harvey RJ: Donepezil for dementia due to Alzheimer's disease. Cochrane Database Syst Rev

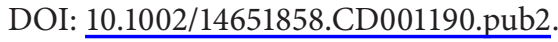

-48 Mega MS, Cummings JL, Fiorello T, Gornbein J: The spectrum of behavioural changes in Alzheimer's disease. Neurology 1996;46:130-135.

-49 Maidment ID, Fox CG, Boustani M, Rodriguez J, Brown RC, Katona CL: Efficacy of memantine on behavioral and psychological symptoms related to dementia: a systematic meta-analysis. Ann Pharmacother 2008;42:32-38.

-50 Gauthier S, Wirth Y, Mobius HJ: Effects of memantine on behavioural symptoms in Alzheimer's disease patients: an analysis of the Neuropsychiatric Inventory (NPI) data of two randomised, controlled studies. Int J Geriatr Psychiatry 2005;20:459-464.

-51 Winblad B, Jones RW, Wirth Y, Stoffler A, Mobius HJ: Memantine in moderate to severe Alzheimer's disease: a meta-analysis of randomised clinical trials. Dement Geriatr Cogn Disord 2007;24:20-27. 